\title{
A Digital Health Intervention (SweetGoals) for Young Adults With Type 1 Diabetes: Protocol for a Factorial Randomized Trial
}

Catherine Stanger ${ }^{1}$, PhD; Tobias Kowatsch ${ }^{2,3}, \mathrm{PhD}$; Haiyi Xie ${ }^{1}$, PhD; Inbal Nahum-Shani ${ }^{4}, \mathrm{PhD}$; Frances Lim-Liberty ${ }^{5}$, MD; Molly Anderson ${ }^{1}$, PhD; Prabhakaran Santhanam ${ }^{2}$, MSc; Sarah Kaden ${ }^{1}$, BA; Briana Rosenberg ${ }^{1}$, MA

${ }^{1}$ Center for Technology and Behavioral Health, Geisel School of Medicine, Dartmouth College, Lebanon, NH, United States

${ }^{2}$ Centre for Digital Health Interventions, Department of Management, Technology, and Economics, ETH Zurich, Zurich, Switzerland

${ }^{3}$ Centre for Digital Health Interventions, Institute of Technology Management, University of St Gallen, St Gallen, Switzerland

${ }^{4}$ Institute for Social Research, University of Michigan, Ann Arbor, MI, United States

${ }^{5}$ Dartmouth-Hitchcock Medical Center, Lebanon, NH, United States

Corresponding Author:

Catherine Stanger, $\mathrm{PhD}$

Center for Technology and Behavioral Health

Geisel School of Medicine

Dartmouth College

46 Centerra Parkway

Lebanon, NH,

United States

Phone: 16036467023

Email: Catherine.stanger@dartmouth.edu

\section{Abstract}

Background: Many young adults with type 1 diabetes (T1D) struggle with the complex daily demands of adherence to their medical regimen and fail to achieve target range glycemic control. Few interventions, however, have been developed specifically for this age group.

Objective: In this randomized trial, we will provide a mobile app (SweetGoals) to all participants as a "core" intervention. The app prompts participants to upload data from their diabetes devices weekly to a device-agnostic uploader (Glooko), automatically retrieves uploaded data, assesses daily and weekly self-management goals, and generates feedback messages about goal attainment. Further, the trial will test two unique intervention components: (1) incentives to promote consistent daily adherence to goals, and (2) web health coaching to teach effective problem solving focused on personalized barriers to self-management. We will use a novel digital direct-to-patient recruitment method and intervention delivery model that transcends the clinic.

Methods: A 2x2 factorial randomized trial will be conducted with 300 young adults ages 19-25 with type 1 diabetes and (Hb) $\mathrm{A}_{1 \mathrm{c}}$ $\geq 8.0 \%$. All participants will receive the SweetGoals app that tracks and provides feedback about two adherence targets: (a) daily glucose monitoring; and (b) mealtime behaviors. Participants will be randomized to the factorial combination of incentives and health coaching. The intervention will last 6 months. The primary outcome will be reduction in $A_{1 c}$. Secondary outcomes include self-regulation mechanisms in longitudinal mediation models and engagement metrics as a predictor of outcomes. Participants will complete 6- and 12-month follow-up assessments. We hypothesize greater sustained $\mathrm{A}_{1 \mathrm{c}}$ improvements in participants who receive coaching and who receive incentives compared to those who do not receive those components.

Results: Data collection is expected to be complete by February 2025. Analyses of primary and secondary outcomes are expected by December 2025.

Conclusions: Successful completion of these aims will support dissemination and effectiveness studies of this intervention that seeks to improve glycemic control in this high-risk and understudied population of young adults with T1D.

Trial Registration: ClinicalTrials.gov NCT04646473; https://clinicaltrials.gov/ct2/show/NCT04646473

International Registered Report Identifier (IRRID): PRR1-10.2196/27109

(JMIR Res Protoc 2021;10(2):e27109) doi: 10.2196/27109 


\section{KEYWORDS}

type 1 diabetes; mhealth; incentives; health coaching; young adults

\section{Introduction}

\section{Type 1 Diabetes in Young Adults}

The incidence of type 1 diabetes (T1D) is rising [1], and T1D results in significant economic costs in the United States, with yearly medical expenditures estimated at approximately $\$ 7$ billion with an additional $\$ 7$ billion in lost wages [2]. T1D also significantly increases mortality, especially among those with above target hemoglobin $\mathrm{A}_{1 \mathrm{c}}\left(\mathrm{HbA}_{1 \mathrm{c}}\right)$ levels [3]. Young adults are a population at unique risk, with only $14 \%$ of young adults aged 18 to 25 years meeting the target $\mathrm{HbA}_{1 \mathrm{c}}$ goal $\left(\mathrm{HbA}_{1 \mathrm{c}} \leq 7 \%\right)$ versus $30 \%$ of those over 30 years [4]. One in 4 young adults aged 18 to 35 years already have one or more medical complications related to their T1D, most commonly renal problems reflecting micro- or macroalbuminuria and/or retinopathy [5]. Furthermore, young adulthood is a critical developmental period when adult habits are formed as patients transition from parental involvement with diabetes management to independence in self-management of their T1D [6,7].

Despite the unique clinical needs of patients in this age group, few interventions have been tested for this high-risk population. A 2017 systematic review found 18 intervention studies for young adults with T1D [8]. Across studies, the most common intervention strategy $(13 / 18,72 \%)$ targeted engaging young adults with clinical services, an important goal, but unfortunately one that did not routinely result in improved glycemic control in most trials. Only 67\% (12/18) of studies reported $\mathrm{HbA}_{1 \mathrm{c}}$ outcomes and, of these, only 2 were randomized, both showing no impact on $\mathrm{HbA}_{1 \mathrm{c}}$. Since this review, several protocols and intervention development studies have been published $[9,10]$; several reported the results of uncontrolled studies with none showing impact on $\mathrm{HbA}_{1 \mathrm{c}}$ to date [11-13] and one showing significant effects on $\mathrm{HbA}_{1 \mathrm{c}}$ for continuous glucose monitor (CGM) use versus blood glucose meters [14]. These results highlight a major gap in and need for more rigorous research on effective ways to improve glycemic outcomes among young adults with T1D.

\section{Intervention Model}

The proposed intervention model offers a multipronged self-regulation approach for targeting glycemic control that is tailored for young adults. The goal of the selected intervention components is to improve self-regulatory mechanisms [15] including self-monitoring, goal setting, self-efficacy about diabetes management, and problem-solving skills. These self-regulatory mechanisms promote improved T1D regimen adherence and $\mathrm{HbA}_{1 \mathrm{c}}$ [16-20]. The conceptual model in Figure 1 highlights the role of self-regulation as an intervention target leading to improved outcomes. To target self-regulation among youth with T1D, we developed a multicomponent intervention that includes (1) weekly diabetes device data upload and data review designed to promote healthy self-monitoring and goal-setting habits for diabetes management and provide feedback about goal attainment, (2) web-based human coaching to deliver motivational interviewing exercises and teach a structured problem-solving method, and (3) motivational incentives to enhance adherence. 
Figure 1. Conceptual model of intervention effects on hemoglobin $A_{1 c}$.

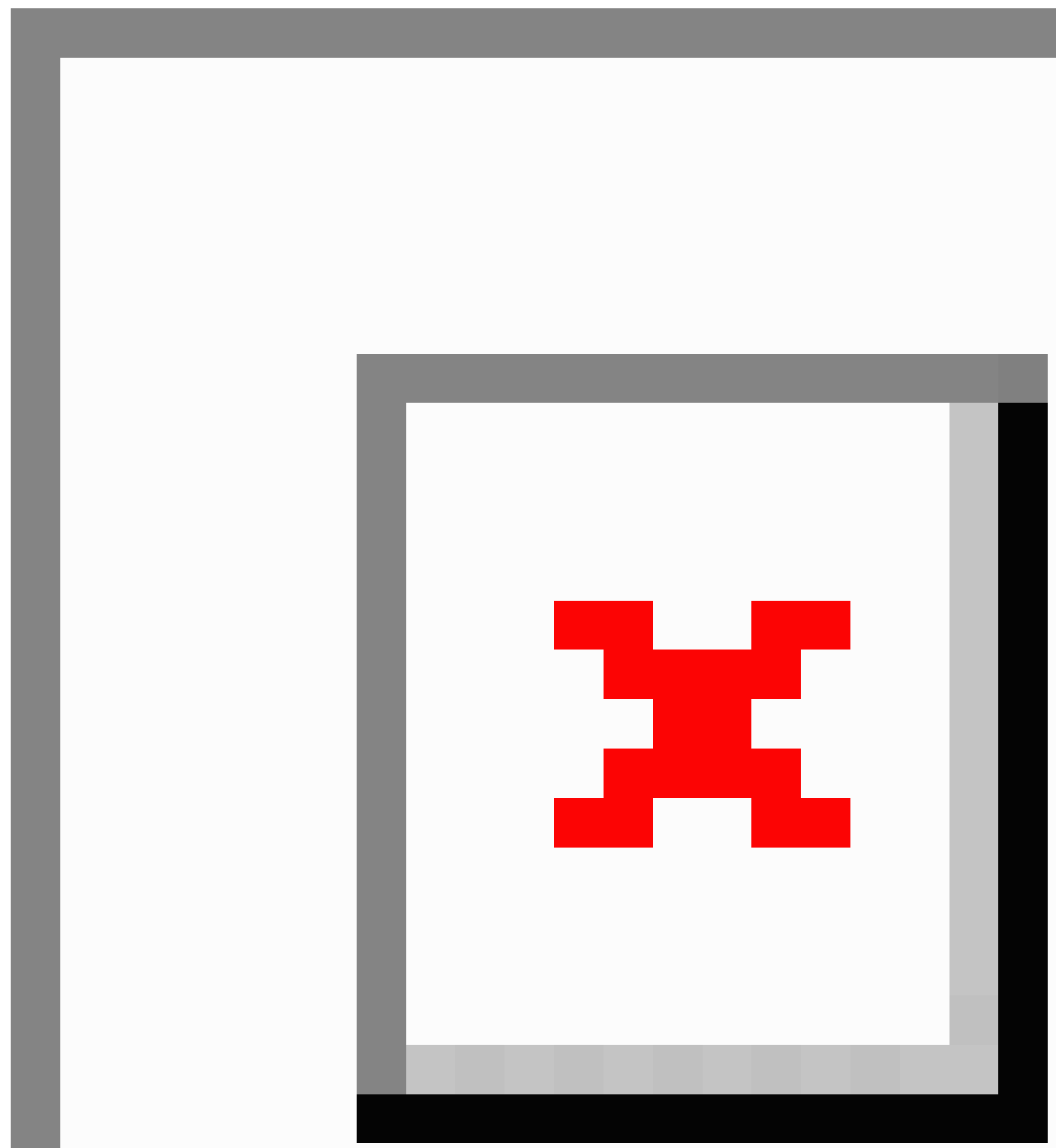

A series of prior iterative studies developed and tested this intervention approach, including a randomized trial comparing a similar intervention to usual care for adolescents aged 13 to 17 years. Intervention youth had significantly lower $\mathrm{HbA}_{1 \mathrm{c}}$ levels at the end of the 6-month intervention $(d=.45)$, and this effect was fully maintained indicating no weakening of the intervention effect at the 12-month follow-up ( $d=.44)$ [21]. Our new study adapted this earlier intervention to enhance both efficacy and disseminability. The primary modification to increase efficacy involves expanding the goal target from glucose checking to encompass the additional key self-management behavior of carbohydrate counting. Enhancements to promote dissemination (and scalability) include (1) modifying goals to encompass the full spectrum of diabetes devices, (2) automating the goal setting and feedback components via an app, and (3) recruiting young adults via social media. In addition, this study uses a factorial design to test the independent effects of incentives to promote consistent daily adherence to goals and web health coaching to teach effective problem solving focused on personalized barriers to self-management, providing better understanding of the intervention mechanisms.

\section{Incentives to Promote Self-Management}

Incentives may be an effective tool for increasing self-management behavior. Because interventions that support self-monitoring of diabetes management have shown limited effects on $\mathrm{HbA}_{1 \mathrm{c}}$, incentives are designed to enhance the impact 
of the intervention on $\mathrm{HbA}_{1 \mathrm{c}}$. Consistent with behavior economic theory [22], most daily adherence behaviors necessary to manage T1D do not result in immediate positive experiences. The benefits from consistent, daily adherence accrue over weeks, months, years, and decades of life. The use of immediate incentives for adherence is one way to increase the value of such behaviors in the present, providing an immediate reason to adhere. In the SweetGoals intervention, incentives target improvement in specific self-management behaviors, and such improvement is expected to improve glycemic control. Three studies [23-25] using incentives for glucose checks have shown significant positive effects, as have our prior studies [21,26,27].

\section{Health Coaching to Improve Self-Regulation}

This study will also test the impact of a coaching intervention focused on enhancing motivation and teaching problem-solving skills to promote long-term outcomes. There is evidence that motivational interviewing and instruction in problem-solving skills can improve medical adherence including in T1D [28-35]. Health coaches will teach these skills in brief web-based sessions in the context of device data review focused on actionable self-management targets. The curriculum begins with motivational exercises to guide selection of concerns that become the target of the problem-solving sessions. The health coach also facilitates engagement with self-monitoring and goal-setting habits using the Glooko data visualization platform and the SweetGoals app goal feedback, consistent with the supportive accountability model [36]. Providing such support increases the efficacy of digital interventions [37-42], and delivery by bachelor's level coaches can be as effective as professional clinicians across diverse clinical targets $[43,44]$. The supportive accountability model emphasizes the key role that social presence (human coach) plays in setting clear expectations regarding adherence to the steps necessary to achieve a positive outcome (eg, glucose monitoring) and in supporting goal attainment via progress monitoring and feedback [36]. Our pilot results strongly support the long-term sustained efficacy of this coaching approach combined with incentives [21], but those results cannot inform the need for both of these distinct interventions. This new study will replicate those earlier results in a novel population of young adults and test the separate impact of incentives, coaching, and their interaction.

\section{Methods}

\section{Participants}

We will enroll 300 young adults with T1D, aged 19 to 25 years (target $50 \%$ female) who have $\mathrm{HbA}_{1 \mathrm{c}} \geq 8 \%$. Young adults must use a Glooko compatible glucometer or CGM and may use either multiple daily injections (MDI) or continuous subcutaneous insulin infusion (CSII). See Textbox 1 for detailed inclusion and exclusion criteria.

Textbox 1. Inclusion and exclusion criteria for the SweetGoals study.

Inclusion criteria:

- Diagnosis of type 1 diabetes for longer than 18 months

- $\mathrm{HbA}_{1 \mathrm{c}} \geq 8.0 \%$

- $\quad$ Report a visit with physician managing type 1 diabetes within the previous 6 months

- $\quad$ Participants must use a glucometer or continuous glucose monitor compatible with Glooko

Exclusion criteria:

- $\quad$ Pregnancy or breastfeeding

- Severe medical illness that would preclude participation (eg, cystic fibrosis, developmental disability, severe cognitive impairment)

- $\quad$ Psychiatric illness that would preclude participation

- Diabetes diagnosis other than type 1 diabetes (type 2 diabetes, maturity onset diabetes of the young)

- Use of any medications known to impact glycemic control (oral or injectable corticosteroids, beta-blockers, antipsychotic medications such as risperidone)

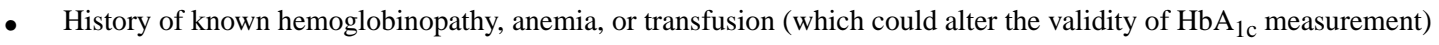

- Already being engaged in a psychological intervention targeting diabetes adherence

\section{Recruitment}

Participants will be recruited using Facebook, Instagram, and Google ads. Best practices for ethical recruitment using social media platforms will be followed $[45,46]$. Breaks will occur between ad runs to reduce ad fatigue. The ads will prompt potential participants to download the SweetGoals app. Once they confirm that they are in the target age range, they will complete the study consent in the app. Consenting participants will complete a brief survey via the app to confirm eligibility.
Research staff will follow up to complete the screening process, confirming device compatibility with Glooko and arranging for completion of the $\mathrm{HbA}_{1 \mathrm{c}}$ test via postal mail. Once eligibility is confirmed (mail-in $\mathrm{HbA}_{1 \mathrm{c}} \geq 8 \%$ ), staff will help participants create their Glooko accounts and install the Glooko uploader and Glooko smartphone app via phone or a web video chat. Staff will then complete the randomization as described below. Figure 2 displays the screening, recruitment, and randomization process. 
Figure 2. Screening, recruitment, and randomization process.
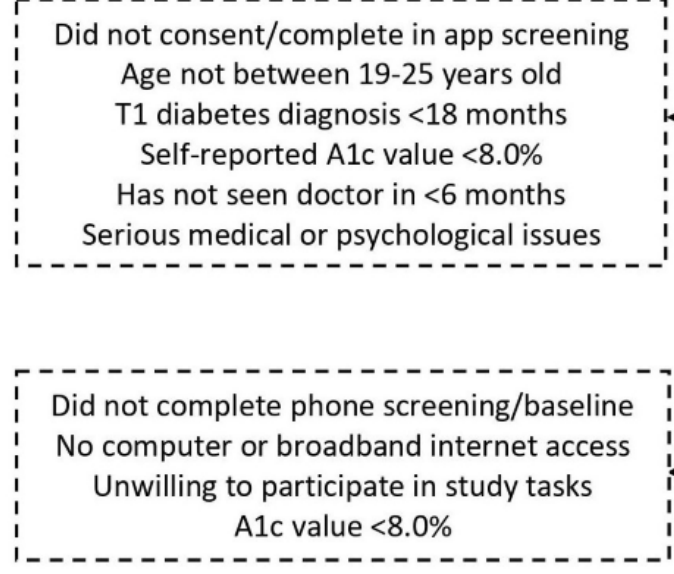

Potential participants download the SweetGoals app

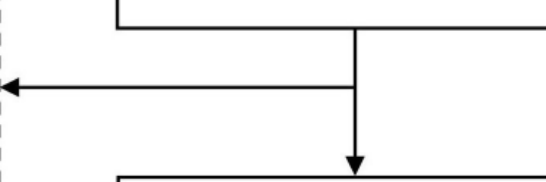

19-25 years old

Diabetes diagnosis for at least 18 months Self-reported A1c $\geq 8.0 \%$

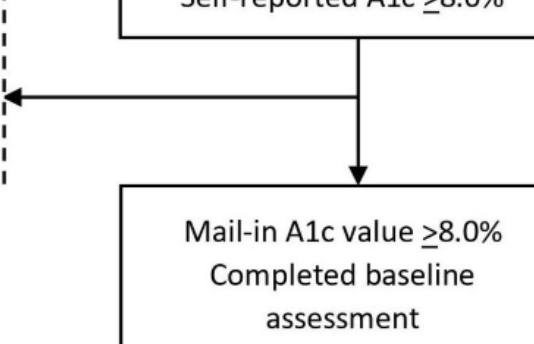

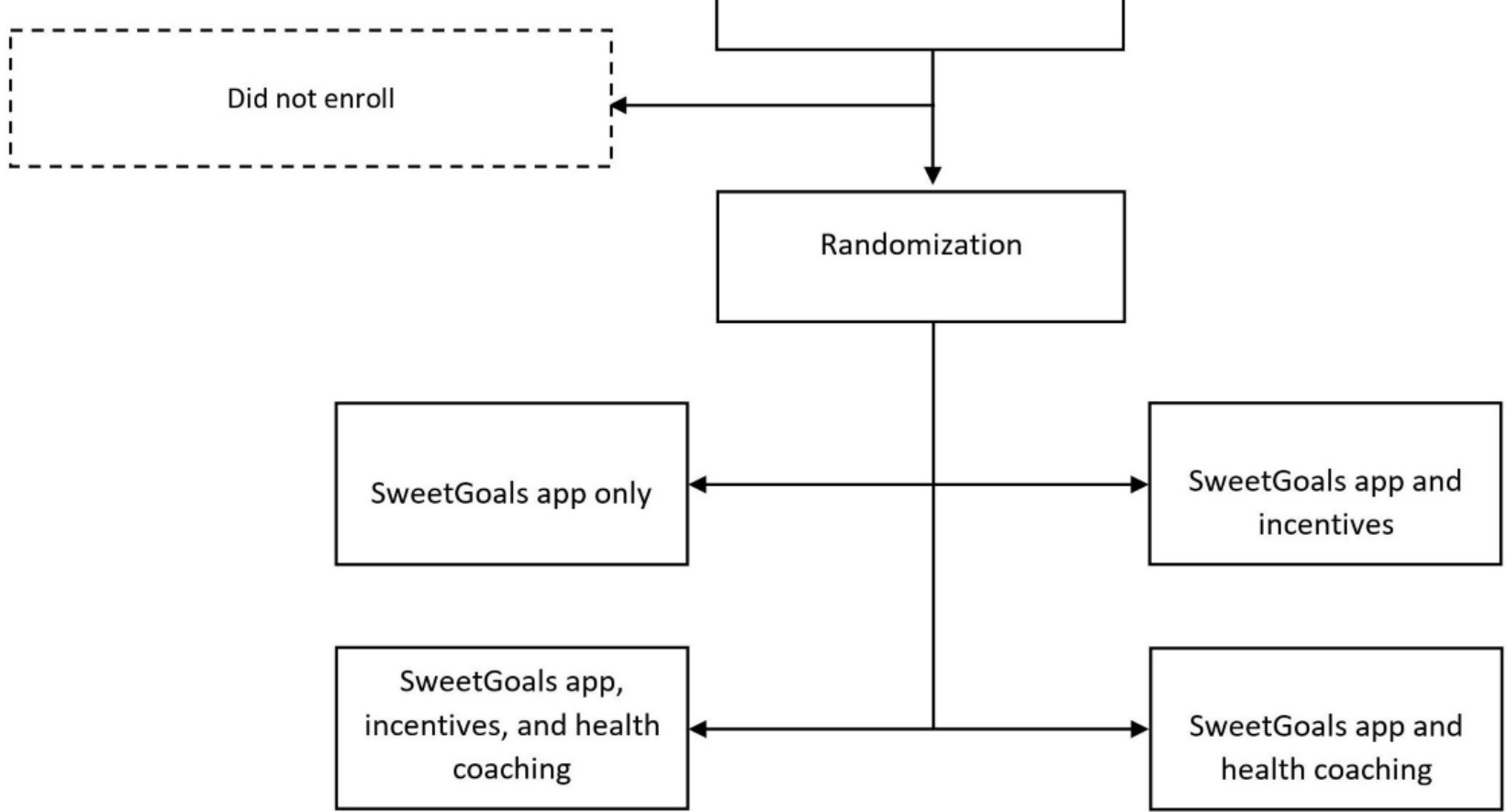

\section{Procedure}

A fully powered $2 \times 2$ randomized factorial experiment (see Table 1) will be used to evaluate specific intervention components in terms of $\mathrm{HbA}_{1 \mathrm{c}}$ outcomes. Factorial designs are a highly efficient experimental approach for answering questions about the utility of multiple intervention components and their combinations. Data from these designs can be used to test the main effect of each intervention component as well as their interaction $[47,48]$. All participants will receive the SweetGoals app. Those assigned to the incentive group will receive incentives for meeting glucose monitoring and mealtime targets. Those assigned to the coaching group will receive web coaching in problem-solving skills focused on achieving better self-management and glycemic control. If assigned to incentives, participants will receive incentives weekly for 3 months, with gradually fading frequency over the next 3 months. If assigned to coaching, participants will meet with the coach weekly via web video for 3 months, with the frequency of those meetings also fading gradually over the next 3 months. The intervention period lasts for 6 months. Follow-up assessments will be completed at 6 months and 12 months after baseline. 
Table 1. Experimental conditions of the $2 \times 2$ factorial design.

\begin{tabular}{llll}
\hline Experimental condition & SweetGoals app & Incentives & Web coaching \\
\hline 1 & Yes & No & No \\
2 & Yes & No & Yes \\
3 & Yes & Yes & No \\
4 & Yes & Yes & Yes \\
\hline
\end{tabular}

Each component will take on 2 levels: yes or no. Note that the factorial design in Table 1 is not a 4-arm trial with each condition compared with a control or to each other. Instead, our interest is in tests of standard analysis of variance main effects and interactions [49]. These involve comparison of outcome means across multiple experimental conditions. For example, the main effect of the incentives component will be tested by comparing the mean of the outcome variable across the 2 conditions in which incentives will be delivered (ie, those in conditions 3 and $4 ; n=150$ before attrition) versus the 2 conditions in which incentives will not be delivered (ie, those in conditions 1 and 2; $n=150$ before attrition). Hence, this main effect will be tested by comparing half of the sample (those offered incentives) versus the other half (those not offered incentives) in terms of the primary outcome. In this factorial experiment, each effect (including the interaction between the 2 components) will be estimated based on data from all 4 conditions (ie, the full sample) [48,50,51].

Figure 3 shows the study design. An online minimization program (MinimPy) will be used to assign participants [52]. Minimization assures similarity across intervention groups on multiple key covariates [52]. Differences between conditions will be minimized on gender, age, ethnicity (minority vs White), CSII versus MDI, CGM use, and $\mathrm{HbA}_{1 \mathrm{c}}$. Follow-ups will occur at 6 months and 12 months. Compensation will be $\$ 25$ for the baseline assessment, $\$ 50$ for each follow-up assessment, and a supplement of $\$ 50$ for completing both follow-ups. This study was approved by the Committee for the Protection of Human Subjects at Dartmouth College and is registered at ClinicalTrials.gov [NCT04646473].

Figure 3. Study design.

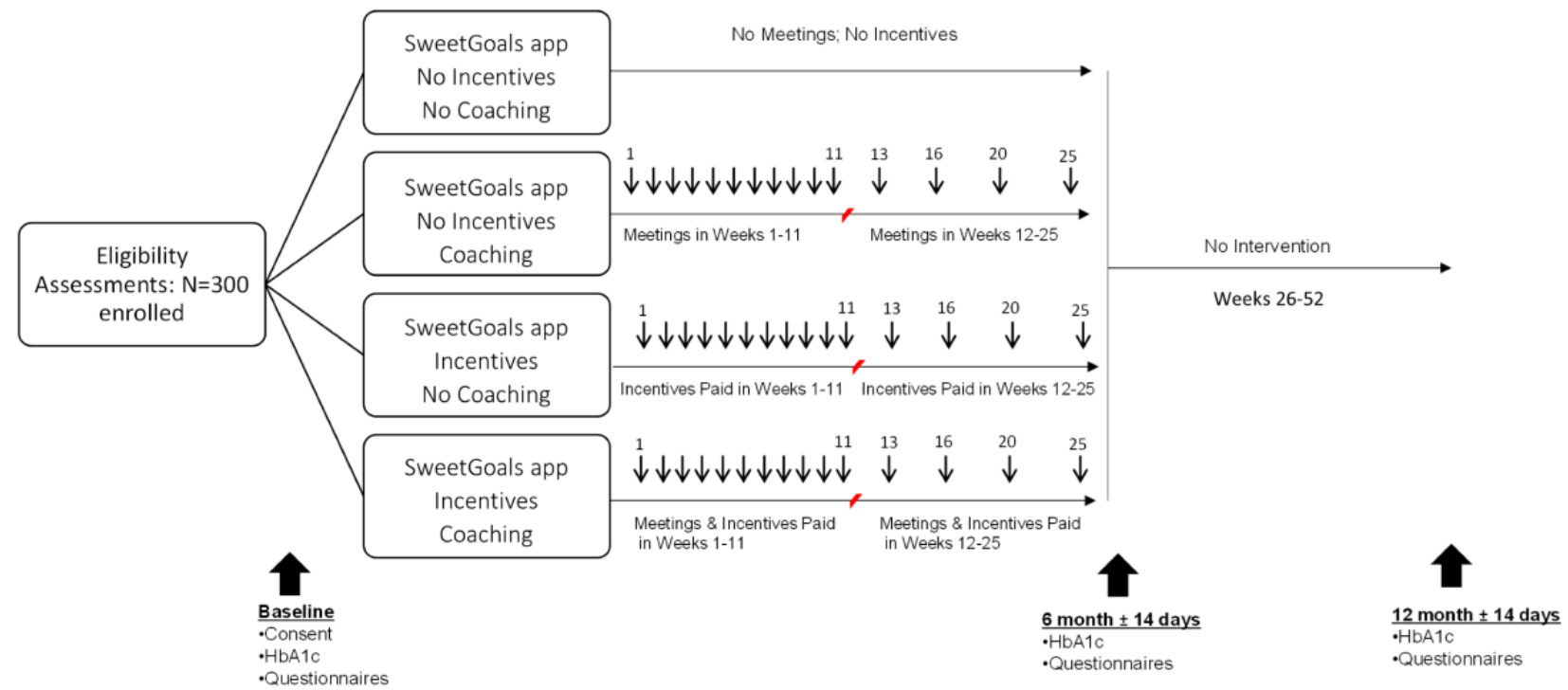

\section{SweetGoals App Core Intervention}

All participants will receive SweetGoals, an app that sends messages about self-management goals, goal adherence, and encouragement about adherence in the upcoming week. Participants will receive messages on Sunday reminding them to upload their data and feedback detailing their goal achievement on Monday. They will also receive educational materials in a second message most weeks (eg, links to information about self-management of T1D). The app is programmed in MobileCoach [53-55], an open-source app platform that has the functionality to integrate our goal-tracking algorithms and provide messages that prompt device uploads and provide automated feedback. MobileCoach sends messages written by the research team in the style of Facebook Messenger or WhatsApp from a digital coach who communicates with the app user to provide scripted feedback about goals as shown in Figure 4. Participants select from a random sample of 4 coaches offered from a bank of 12 coaches of diverse gender and race/ethnicity. The participant (Briana in Figure 4) can answer the digital coach (Taylor in Figure 4) using predefined responses. 
Figure 4. SweetGoals dialogue with digital coach Taylor.

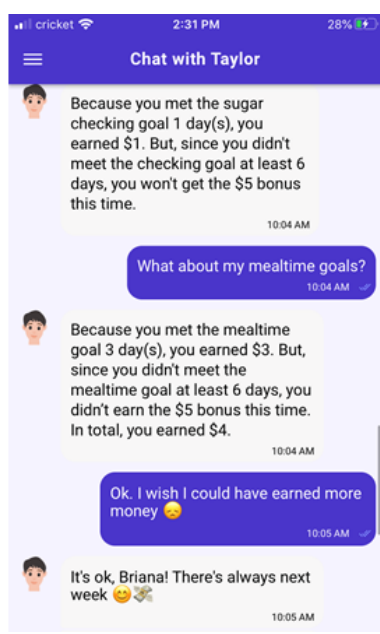

\section{Daily and Weekly Self-Management Goals}

The SweetGoals app will automatically download the participant's device data each Sunday at midnight using the Glooko application programming interface. The app will use the device data to provide feedback each Monday about goals that target glucose monitoring and mealtime behaviors tailored by device as shown in Table 2 . The glucose monitoring goal for participants who use a glucometer only (no CGM) is $\geq 5$ checks, each $\geq 2$ hours from another check. Additional checks - regardless of spacing-are encouraged based on clinical needs (eg, hypoglycemia). This same criterion was used successfully in prior studies [21,26,27]. For participants who use CGM, we conservatively define adequate daily CGM wear time as $80 \%$ of expected values each day. We selected this daily glucose monitoring goal to provide clinically meaningful data to the participant but also allow for legitimate disconnect time (sports, leisure activities) and sensor changes.

Table 2. Goals based on devices used.

\begin{tabular}{llll}
\hline Glucose monitoring device & Insulin delivery method & Glucose monitoring goal & Mealtime goal \\
\hline Glucometer & MDI $^{\mathrm{a}}$ & $\mathrm{SMBG}^{\mathrm{b}}$ & Enter in Glooko Mobile \\
Glucometer & CSII $^{\mathrm{c}}$ & SMBG & Enter in pump \\
$\mathrm{CGM}^{\mathrm{d}}$ & $\mathrm{MDI}$ & $\mathrm{CGM}$ wear time & Enter in Glooko Mobile \\
$\mathrm{CGM}$ & $\mathrm{CSII}$ & CGM wear time & Enter in pump \\
\hline
\end{tabular}

${ }^{\mathrm{a}} \mathrm{MDI}$ : multiple daily injections.

${ }^{\text {b}}$ SMBG: self-monitored blood glucose.

${ }^{c}$ CSII: continuous subcutaneous insulin infusion.

${ }^{\mathrm{d}}$ CGM: continuous glucose monitor.

The mealtime goal for participants who use a glucometer only (no CGM) is to check their glucose before they enter their carbs. Those who use MDI will enter their carb counts in the Glooko app. Participants who use CSII will enter their carb value in their pump. A glucose check must be documented within 30 minutes of the carb entry, an evidence-based criterion [56] that should occur at least 3 times per day according to clinical practice guidelines [57]. An algorithm based on the type of devices used will evaluate whether the mealtime goal was met. The daily mealtime target is 3 properly timed paired glucose levels and carb count values.
The weekly goal for all participants is to meet the daily goal on 6 or more days per week. Each week, participants will also be asked to set personal goals for the next week for the number of days they think they can meet each daily goal, to help participants build motivation to gradually increase their self-management behaviors. Each week, participants will receive feedback messages and graphical reports about goals met (see Figure 5 for an example of a participant who uses a CGM). The app will send reminders to upload device data and set personal goals. 
Figure 5. SweetGoals goal feedback graphs—continuous glucose monitor user.

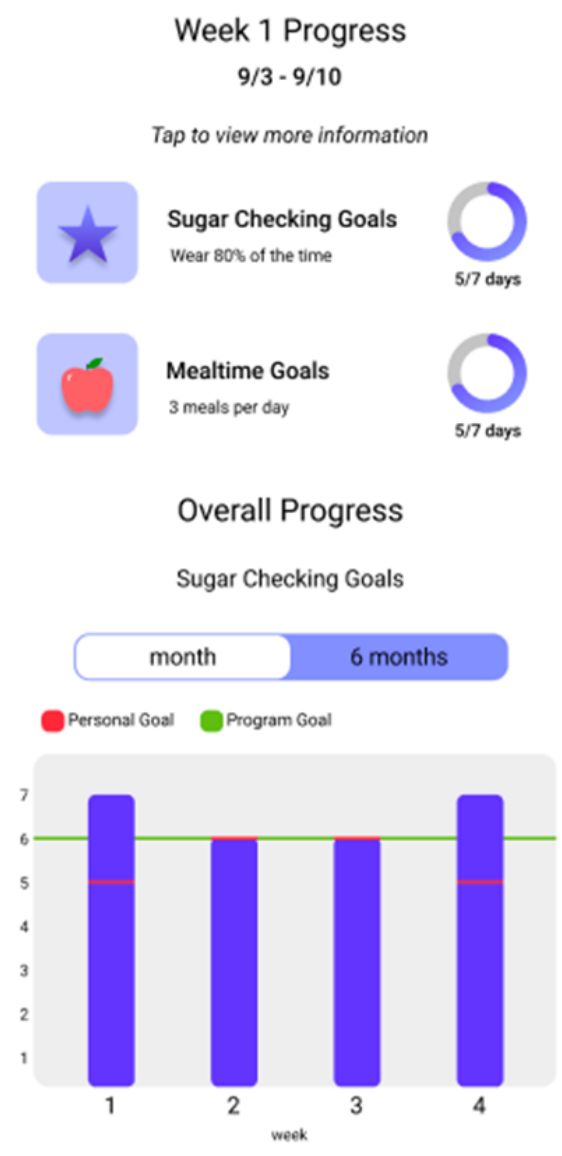

\section{Incentives Component}

Participants assigned to the incentive group will earn \$1 per day for meeting each daily goal (glucose monitoring, mealtime behaviors) and will receive a $\$ 5$ bonus for meeting the weekly target of 6 or more days per week meeting each goal, for a total of $\$ 24$ maximum per week (approximately $\$ 3.50$ per day). The maximum earnings for all goals are $\$ 600$ across 25 weeks. The app will provide messages and graphical reports about incentives (see Figure 6). Incentives accrue weekly throughout the 25 weeks but are paid weekly from weeks 1 to 11 , with payments fading in frequency from weeks 12 to 25 (ie, paid at weeks 13 , 16, 20, and 25). Fading of reinforcement delivery has been shown in human and animal research to engender resistance to extinction after reinforcers end, increasing the maintenance of behavior change beyond the intervention period [58-62]. For this reason, we have incorporated a lengthy (3-month) fading period to promote maintenance of improvements in daily self-management. 
Figure 6. SweetGoals incentives feedback graphs.

\section{Total Earnings}

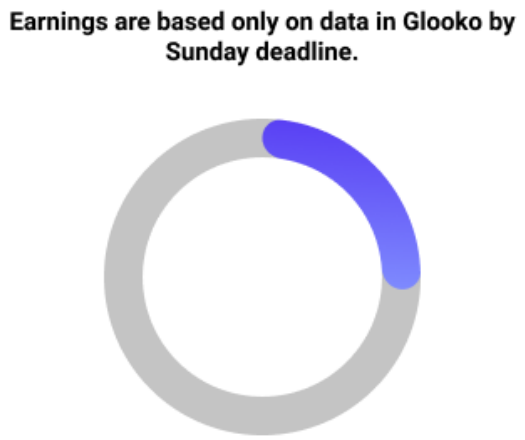

Earned: \$47

Available: $\$ 552$

\section{$\langle$ Weekly Earnings >}

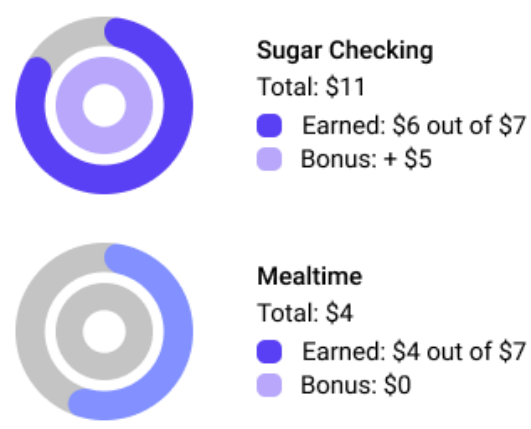

This fading procedure is used to promote habit automaticity and long-lasting improvements in adherence and $\mathrm{HbA}_{1 \mathrm{c}}$. We have successfully used this fading paradigm in our prior studies, which resulted in no weakening of intervention effects on $\mathrm{HbA}_{1 \mathrm{c}}$ up to 6 months after the end of the intervention.

\section{Web Health Coaching Component}

Participants assigned to the coaching group will receive 16 web health coaching sessions by a bachelor's level health coach. Weekly coaching sessions occur from weeks 1 to 11 , and then fade over the second half of the intervention with 4 sessions held during weeks 12 to 25 (weeks 13, 16, 20, and 25). Coaches will use their own chat interface in SweetGoals and text messages to communicate with participants. Coaches will also remind participants of meetings, offer encouragement, and respond to any messages the participant sends. In each meeting, coaches will review weekly glucose monitoring and mealtime goals and incentives earned in the context of diabetes device data reviewed using the Glooko website. Motivational exercises are completed in the first few meetings to develop rapport and allow the young adult to explore and reflect on their self-management strengths and challenges [63]. The young adult will work together with the coach to identify barriers to adherence. Coaches will also teach a structured problem-solving method to the young adult [64].
During the second half of the intervention, as coaching sessions are spaced at increasing intervals, participants are encouraged to review their diabetes data weekly on the Glooko website or app and complete the problem-solving steps on their own to address self-management concerns. Success and challenges with independent problem solving are reviewed at coaching sessions during the fading period. Throughout the intervention, if the young adults experience challenges meeting glucose monitoring or mealtime goals, coaches encourage them to use the problem-solving steps to develop a plan to improve adherence. As they gain more success meeting those goals, they are encouraged to select new goals regarding glucose levels and problem solve potential barriers to achieving those goals. Participants are always encouraged to reach out to their providers with any concerns about the insulin regimen, hypoglycemia, or hyperglycemia as coaching does not address medical management of diabetes. The structure of the problem-solving method is constant across participants; however, the content is highly personalized based on the unique challenges faced by each young adult.

Coaches receive training in communication skills consistent with a motivational interviewing approach [65]. Importantly, motivational interviewing has been identified as an effective approach for improving diabetes outcomes clinical trials 
$[35,66,67]$. Coaches are also trained in providing instruction and support in problem-solving $[64,68]$. Training involves didactic material and extensive role play practice.

\section{Diabetes Care}

Participants in all conditions will receive ongoing diabetes treatment from their current medical provider. Study staff will not provide medical care or intervention. The project includes an endocrinologist who will monitor device data regularly in Glooko, and research staff will encourage participants to follow-up with their medical provider as necessary.

\section{Measures}

Measures will be collected at baseline, 6 months (end of intervention), and 12 months unless otherwise noted. Assessments will not be blinded. All measures will be completed by participants online via the app or LimeSurvey or are objective measures (eg, device downloads, $\mathrm{HbA}_{1 \mathrm{c}}$ tests, or recorded directly via the app).

\section{Demographic Characteristics}

At baseline, demographics will be collected (eg, age, sex, race/ethnicity, insurance type). We will assess socioeconomic status using a single item measure appropriate for young adults [69]. We will assess diabetes indicators (eg, duration of diabetes, device use, past 12-month frequency of severe hypoglycemic events defined as episodes of documented or presumed low blood glucose that resulted in seizure or loss of consciousness [70] and hospitalization for diabetic ketoacidosis). Additionally, we will ask if the participant has been suspected of having a COVID-19 infection.

\section{Primary Outcome}

The primary outcome will be $\mathrm{HbA}_{1 \mathrm{c}}$ assessed using a Clinical Laboratory Improvement Amendments-waived nonfasting whole blood $\mathrm{HbA}_{1 \mathrm{c}}$ test (AccuBase $\mathrm{A}_{1 \mathrm{c}}$ test kit by DTI Laboratories) mailed to the participant (with a postpaid return envelope) at each assessment. Samples are stable at room temperature for 21 days after collection, and results are available within 48 hours of receipt. AccuBase is FDA-cleared and uses capillary tube collection. Lab testing uses high-performance liquid chromatography, including abnormal hemoglobin screening. This method has been used effectively in a large national web-based study [71].

\section{Secondary Outcomes}

Secondary outcomes will include key self-regulation constructs including adherence, self-efficacy, and problem solving. Adherence to glucose monitoring and mealtime behaviors will be assessed during the 30 days prior to each assessment by calculating the percentage of days meeting each goal from device data. Diabetes management self-efficacy and outcome expectations will be assessed using the 10-item Self-Efficacy for Diabetes Management scale [72] that has shown strong relations with adherence among young adults with T1D [16]. Problem-solving skills will be assessed using the 10-item version of the Social Problem-Solving Inventory-Revised $(\alpha=.85)$ $[73,74]$. To assess symptoms of diabetes distress (a moderator), the 28-item T1-Diabetes Distress scale $(\alpha=.91)$ [75,76] will be used. Additionally, behavioral and emotional problems will be assessed with the 34-item version of the Counseling Center Assessment of Psychology Symptoms ( $\alpha=.91$ with all items), with the suicidality and desire to harm others items removed [77]. Self-regulation will be assessed using a brief self-regulation scale [78], a 12-item measure. Body awareness will be measured with the Body Awareness Questionnaire (18 items; $\alpha=.82$ ) [79]. Hypoglycemia awareness will be measured by a single item [80]. Baseline levels of technology experience will be measured using the Technology Readiness Index (16 items) [81] and a novel measure based on Venkatesh et al [82] which asks about experience with specific types of technologies. We will also assess past 30-day substance use frequency (tobacco, alcohol, cannabis, other drugs) with items adapted from the 2018 Monitoring the Future survey [83], the National Survey on Drug Use and Health [84], and the Tobacco, Alcohol, Prescription medication, and other Substance use tool [85].

\section{Implementation, Satisfaction, and App Metrics}

For participants who receive human coaching, satisfaction with the human health coach will be assessed at the beginning, during, and the end of the program with the Session Alliance Inventory $(\alpha=.94)[86]$ and an adaption of the Working Alliance Inventory $[87,88]$. Satisfaction with the SweetGoals digital coach will be assessed at the beginning, during, and at the end of the program with the Session Alliance Inventory [86] and (at the end of the 6-month intervention period only) an adaption of the Working Alliance Inventory [87,88]. We will assess usability of the app components with items from the Usefulness, Satisfaction, and Ease of Use questionnaire $(\alpha=.98)$ [89] and overall app satisfaction with items adapted from Wixom \& Todd [90] 3 times (early, midway, and at the end of the 6-month intervention period). In addition, the app will collect engagement metrics including the percentage of messages from digital coaches responded to within 24 hours of receipt and the mean length of the delay between when messages are sent by the app and accessed by the participant. These data will be used to explore objective app engagement and whether satisfaction and app engagement were better when receiving incentives or coaching.

\section{Health Coaching Fidelity}

Coaches will complete a detailed checklist after each meeting. In addition, fidelity coding of one randomly selected session for each participant will be completed [91]. Undergraduate coders will complete an extensive training protocol in the rating system. Coders will double code a randomly selected subset (25\%) of sessions, and reliability will be tracked on an ongoing basis to ensure reliability of more than $80 \%$.

\section{Statistical Analysis}

All subjects, once randomized, will be included in the intent-to-treat sample. We will strive to collect all primary and secondary outcomes even if a participant does not engage in assigned interventions. Data will be stored in the Research Electronic Data Capture, MobileCoach, and a secure Dartmouth server. 


\section{Missing Data}

As in any study, missing values may occur due to dropout (anticipated to be less than $20 \%$ by the end of 12 months), inability to reach a participant for follow-up, item nonresponse, or gaps in or missing device data. The proposed structural equation modeling (SEM) and linear mixed effects models (LMMs) use all available data and are robust to outcome data that are missing at random.

\section{Primary Outcome Analyses}

The primary aim is to test the main effects of incentives and coaching on $\mathrm{HbA}_{1 \mathrm{c}}$. We will also test the interaction between components (eg, the synergistic effect of adding one component to another). Two effect-coded indicators (see Collins [51] for detailed justification for using effect coding in the analysis of data from factorial designs) will be created, one for each component: the indicator for incentives (yes vs no) will differentiate between those offered incentives (coded +1 ; conditions 3 and 4 in Table 1) and those who were not (coded -1 ; conditions 1 and 2 in Table 1); the indicator for coaching (yes vs no) will differentiate between those offered coaching (coded +1 ; conditions 2 and 4 in Table 1) and those who were not (coded -1 ; conditions 1 and 3 in Table 1). To assess the impact of each component on $\mathrm{HbA}_{1 \mathrm{c}}$ over time (baseline, 6 months after, and 12 months after), an LMM will be fit. The model will include fixed effects for time, two component indicators, the component $\times$ component interaction, two component $\times$ time interactions, and the component $\times$ component $x$ time interaction as fixed effects. The LMM will also include random effects for the intercept and time to account for within-person correlation. Based on this LMM, we will test the hypothesis that the yes level of each component (vs no) results in lower $\mathrm{HbA}_{1 \mathrm{c}}$ over time via the component $\times$ time interaction parameters.

We calculated the power for testing effects on $\mathrm{HbA}_{1 \mathrm{c}}$ based on the following assumptions: (1) models will include baseline $\mathrm{HbA}_{1 \mathrm{c}}$; (2) a within-person correlation between baseline $\mathrm{HbA}_{1 \mathrm{c}}$ and $\mathrm{HbA}_{1 \mathrm{c}}$ at each follow-up assessment of 0.6 (based on our pilot study); and (3) a standard deviation for $\mathrm{HbA}_{1 \mathrm{c}}$ of 1.2, based on our pilot data. Table 3 shows detectable main effects and interactions in terms of Cohen $d$ [92] and $\mathrm{HbA}_{1 \mathrm{c}}$ mean differences. Given $\mathrm{n}=240$ to $\mathrm{n}=270$ (based on $80 \%$ to $90 \%$ retention), we will be able to detect small effect sizes (Cohen $d=0.27$ to $d=0.29$ ) with $80 \%$ power.

Table 3. Aim 1 power for main effects and interaction between components.

\begin{tabular}{llllll}
\hline Retention $\%$ & $\mathrm{~N}$ & Power $\%$ & 2-sided $P$ value & Cohen $d$ & HbA $_{1 \mathrm{c}}$ difference $\%$ \\
\hline 90 & 270 & 80 & .05 & 0.27 & 0.32 \\
85 & 255 & 80 & .05 & 0.28 & 0.33 \\
80 & 240 & 80 & .05 & 0.29 & 0.35 \\
\hline
\end{tabular}

\section{Secondary Outcome Analyses}

Secondary analyses will evaluate change in 4 potential mechanisms of action of incentives and coaching (and their interaction) on $\mathrm{HbA}_{1 \mathrm{c}}$ at 6 months: glucose monitoring adherence, mealtime adherence, self-efficacy, and problem solving. We will follow the methods recently outlined for conducting mediation analysis in a factorial design with multiple mediators [93]. The mediation model will be tested using SEM with full maximum likelihood estimation, as outlined by MacKinnon et al [94]. The models will test effects of (1) each component and their interaction on the 4 mediators assessed at 6 months, (2) each mediator on $\mathrm{HbA}_{1 \mathrm{c}}$ at 12 months, and (3) each component and their interaction on $\mathrm{HbA}_{1 \mathrm{c}}$ at 12 months. Models will control for baseline levels of $\mathrm{HbA}_{1 \mathrm{c}}$ and the mediators. This model will evaluate the indirect effect of each component on $\mathrm{HbA}_{1 \mathrm{c}}$ through each mechanism, thereby testing whether the effect of coaching and incentives on $\mathrm{HbA}_{1 \mathrm{c}}$ is through increasing each of the 4 potential mechanisms.

\section{Exploratory Analyses}

Informed by the approach of Yardley et al [95], these analyses aim to determine whether app engagement and use metrics predict improvements on $\mathrm{HbA}_{1 \mathrm{c}}$ outcomes. We will first examine how engagement metrics differ between those receiving incentives versus no incentives and coaching versus no coaching. Use metrics will include the percentage of messages responded to within 24 hours of receipt and the mean length of the delay between when messages are sent and accessed. In LMM models predicting $\mathrm{HbA}_{1 \mathrm{c}}$, we will adjust for one or both components if we find significant component effects on engagement metrics. Effects of engagement metrics on $\mathrm{HbA}_{1 \mathrm{c}}$ outcomes are of interest in terms of future refinement and development of the SweetGoals app, suggesting critical app features that may be important to retain in future interventions or features that appear to have less impact and may need to be improved upon in future research [95].

\section{Results}

We anticipate recruiting 300 young adults in a 36-month period (approximately 8 per month). The anticipated date of enrollment of the first participant is February 2021. We expect that data collection will be complete by February 2025. We expect to complete analyses of the primary and secondary outcomes by December 2025.

\section{Discussion}

\section{Design Innovations}

This study focuses on investigating the utility of two intervention components, seeking to optimize an intervention for improving glycemic outcomes among young adults with T1D. Innovations include recruiting participants with T1D into an intervention 
via social media and intervention delivery via an app plus coaching and incentives both delivered remotely, strategies that may be vital to reaching the targeted, understudied, and underserved population of young adults. In addition, this is the first intervention designed to target adherence via incentives among patients using diverse glucose measurement methods (glucometer, CGM) and methods of insulin delivery (MDI, CSII). This trial also makes innovative use of existing diabetes device technology by integrating a diverse array of devices with an app to automate tracking of and feedback on daily adherence habits. This digital and web-based model is designed to be broadly applicable across the range of health conditions in which patients struggle with self-management.

\section{Design Considerations}

The study design was informed by research evidence across multiple domains. For example, the focus on young adults was based on evidence suggesting they are at unique risk for above target $\mathrm{HbA}_{1 \mathrm{c}}$ levels and that periods of above target $\mathrm{HbA}_{1 \mathrm{c}}$ levels during these years have a long-lasting negative impact on health [96]. We chose to focus on early young adulthood (ages 19 to 25 years) due to their higher risk for above target $\mathrm{HbA}_{1 \mathrm{c}}$ [97] and possible developmental differences across the later 20 s and early 30s. Further, we chose to target young adults outside the traditional clinic setting directly via social media, empowering them to address their diabetes self-management. Many young adults are less compliant with obtaining regular medical care [98], which suggests it may be important to offer services to young adults with T1D outside the endocrinology setting to problem solve their barriers to clinical care and encourage them to schedule regular visits with their provider. This proposed model focuses on directly engaging participants rather than targeting changes in provider behavior. As such, it offers a practical outreach approach that could be deployed nationally and adopted by medical practices, health systems, or insurers outside of office visits to engage young adults with T1D in working together with their provider and managing their own health.

\section{Intervention Targets}

There were several decisions made in relation to our choice of particular adherence behaviors to target. Key to effectively using incentives to change behavior is the identification of specific, objectively verifiable, targets. Research on diabetes has long identified self-monitored blood glucose (SMBG) as a fundamental adherence behavior related to better glycemic control [99], and our pilot research focused on increasing SMBG. However, the increasing use of CGM (approximately $25 \%$ in the T1D Exchange sample [97]) led us to develop a strategy to include all participants with above target $\mathrm{HbA}_{1 \mathrm{c}}$, using any combination of diabetes devices. This choice required us to identify a key adherence behavior necessary for CGM use to have a positive impact on glycemic control. Research suggests that CGM wear time is the analog to SMBG that positively impacts glycemic control [100]. Of note, high wear time is defined as providing $80 \%$ of expected glucose values each day, based on a review of CGM studies and the recent international consensus statement [101]. By selecting targets that allow the inclusion of participants using all current glucose monitoring devices, we have greatly increased the intervention generalizability.

There are many other self-management behaviors in addition to glucose monitoring necessary to achieve below target $\mathrm{HbA}_{1 \mathrm{c}}$ levels, and these primarily reflect timely and accurate insulin dosing. In selecting additional specific, objectively verifiable targets related to insulin dosing we needed to address multiple challenges. Some of these include the different regimens and rules associated with use of MDI versus CSII, highly individualized insulin dosing regimens across participants, and diverse circumstances under which the dosing rules should be altered (eg, when ill, due to exercise, due to nutritional factors other than simply the number of carbs consumed). It is also not possible to objectively verify for a patient who uses MDI the timing and amount of insulin delivered. For these reasons, we opted to focus on mealtime behaviors involving a glucose value less than 30 minutes prior to an entered carb value, a pair of behaviors that are fundamental to accurate insulin dosing and that are required of all participants regardless of method of insulin dosing.

Ideally, mealtime adherence reflects 3 steps: a properly timed glucose check, entry of the number of carbs consumed, and correct insulin dosing. There are few data regarding carb counting among young adults who do not use CSII. However, research has investigated adherence among young adults using CSII [56,102-106]. Overall, adherence is highly variable across individuals, and days on which a mealtime bolus occurs more than 3 times are significantly correlated with $\mathrm{HbA}_{1 \mathrm{c}}$ [103,105,107,108]. Participants who complete these first two steps (glucose check and carb entry) are likely to deliver a bolus, as supported by research showing that the sequence of a properly timed glucose check and a carb entry without a bolus occurred less than $1 \%$ of the time [56].

In selecting adherence targets, we also considered targeting individual glucose levels or time in the target glucose range. Unfortunately, for participants who do not use CGM, these data are sparse and potentially not representative of daily fluctuation in glucose levels. Our selected mealtime behaviors are more actionable and are key adherence behaviors for participants using CGM, even when hybrid closed-loop systems are in widespread use [109-114]. Further, access to such systems is often allowed only for participants showing adherence and moderate $\mathrm{HbA}_{1 \mathrm{c}}$ elevations. For example, in the recent closed-loop study with patients with above target $\mathrm{HbA}_{1 \mathrm{c}}$ levels, participants with $\mathrm{HbA}_{1 \mathrm{c}}>10 \%$ were excluded and participants were required to show use of CGM for at least 12 days and use of the bolus calculator for at least $75 \%$ of meal boluses over 2 weeks prior to randomization [115]. Finally, discontinuation rates for such systems may be high [116], suggesting the continued need for solutions to improve outcomes for participants using diverse treatment regimens.

\section{Inclusion of Incentive Component}

Some research on the use of incentives to promote health behavior related to diabetes have not shown significant benefits. For example, a scoping review [117] reported that using incentives for health behavior related to type 2 diabetes showed 
limited efficacy. The review highlights several critical issues related to the design of incentive interventions that can result in poor outcomes. For example, ineffective incentive programs typically offer infrequent rewards provided long after the target behavior occurs. To be effective, incentives should be provided frequently and immediately after the targeted behavior. Ineffective programs often target one-time behaviors (eg, attending a clinic visit). Instead, incentives should target learning new, daily healthy habits. Consistent with best practices, our intervention uses immediate rewards, focuses on daily health behaviors, incorporates behavioral economic principles of goal setting to engage commitment to behavior change, and provides frequent feedback.

Concern is sometimes expressed that incentives may undermine intrinsic motivation; however, the undermining effect of rewards on intrinsic motivation appears limited to simple tasks for which motivation is initially high [118]. When baseline levels of incentivized behaviors (and motivation) are low (as they generally are for health-related behaviors such as adherence among those with above target $\mathrm{HbA}_{1 \mathrm{c}}$ ), there is no evidence for a negative impact on intrinsic motivation [119]. In fact, studies have shown that incentive interventions can increase intrinsic motivation [120] and engage deliberative cognitive processes related to self-regulation to offset automatic selection of unhealthy but reinforcing behaviors [121]. Incentives can also build sustained habits [122], and habits with high automaticity may be stronger predictors of health behavior than positive intentions $[123,124]$.

Because concern is sometimes raised about the potential for dissemination of financial incentive interventions, this study will experimentally test the impact of the incentive component of SweetGoals. In recent years, use of incentive interventions has greatly expanded across the United States. These include deploying incentives for abstinence from substance use across 94 locations in the Veterans Affairs system [125], workplace wellness programs (offered by $80 \%$ of employers with more than 1100 employees) many of which include financial incentives or penalties for employees with chronic conditions [126], offering financial incentives specific to diabetes or prediabetes (type 2 diabetes) conducted in federally qualified health centers and large health systems (Kaiser Permanente, Cleveland Clinic) [127-131], and programs offering incentives for Medicaid enrollees with prediabetes for weight loss [132] and for enrollees with hypertension or diabetes who meet health targets [133]. These efforts show the increasing dissemination of the use of financial incentives to change health behaviors in the United States and highlight the need to enhance science-based guidance to inform such programs.

\section{Conclusion}

This study is designed to test the role of two evidence-based behavioral intervention components (incentives and health coaching) in supplementing a mobile health approach to improve glycemic outcomes among high-risk young adults with T1D who have above target $\mathrm{HbA}_{1 \mathrm{c}}$ levels. We will also test the effect of these intervention components on key self-regulatory mechanisms hypothesized to be impacted by these components, including two aspects of adherence (glucose monitoring and mealtime behaviors), plus self-efficacy and problem solving. Overall, results will provide critical data on enhancements to a digital intervention for T1D that are highly disseminable. They will also advance the field of theoretically driven interventions aimed at improving self-management and glycemic outcomes among high-risk young adults with elevated $\mathrm{HbA}_{1 \mathrm{c}}$ levels.

\section{Acknowledgments}

This research was funded by a grant from the National Institute of Diabetes and Digestive and Kidney Diseases (R01DK124428). This funding source had no role in the design of this study and will not have any role during its execution, analyses, interpretation of the data, or decision to submit results.

\section{Authors' Contributions}

CS, TK, HX, IN, and FL were responsible for the study design. PS developed the SweetGoals app. CS, MA, SK, and BR developed the study protocol. CS, HX, and IN were responsible for the data analysis plan. CS and SK wrote the first draft. All authors were responsible for critical feedback and final revisions of the manuscript.

\section{Conflicts of Interest}

TK and PS are affiliated with the Center for Digital Health Interventions [134], a joint initiative of the Department of Management, Technology, and Economics at ETH Zurich and the Institute of Technology Management at the University of St. Gallen, which is funded in part by the Swiss health insurer CSS (Christian Social Health Insurance Company of Switzerland). TK is a founder of Pathmate Technologies, a university spin-off company that creates and delivers digital clinical pathways. Neither CSS nor Pathmate Technologies were involved in any way in this manuscript.

\section{References}

1. Mayer-Davis EJ, Lawrence JM, Dabelea D, Divers J, Isom S, Dolan L, SEARCH for Diabetes in Youth Study. Incidence trends of type 1 and type 2 diabetes among youths, 2002-2012. N Engl J Med 2017 Dec 13;376(15):1419-1429 [FREE Full text] [doi: 10.1056/NEJMoa1610187] [Medline: 28402773] 
2. Tao B, Pietropaolo M, Atkinson M, Schatz D, Taylor D. Estimating the cost of type 1 diabetes in the U.S.: a propensity score matching method. PLoS One 2010 Jul 09;5(7):e11501 [FREE Full text] [doi: 10.1371/journal.pone.0011501] [Medline: 20634976]

3. Mameli C, Mazzantini S, Ben Nasr M, Fiorina P, Scaramuzza AE, Zuccotti GV. Explaining the increased mortality in type 1 diabetes. World J Diabetes 2015 Jul 10;6(7):889-895 [FREE Full text] [doi: 10.4239/wjd.v6.i7.889] [Medline: 26185597]

4. Miller KM, Foster NC, Beck RW, Bergenstal RM, DuBose SN, DiMeglio LA, et al. Current state of type 1 diabetes treatment in the U.S.: updated data from the T1D Exchange clinic registry. Diabetes Care 2015 Jun;38(6):971-978. [doi: 10.2337/dc15-0078] [Medline: 25998289]

5. Zoffmann V, Vistisen D, Due-Christensen M. A cross-sectional study of glycaemic control, complications and psychosocial functioning among 18- to 35-year-old adults with type 1 diabetes. Diabet Med 2014 Apr;31(4):493-499. [doi: 10.1111/dme.12363] [Medline: 24236961]

6. Monaghan M, Helgeson V, Wiebe D. Type 1 diabetes in young adulthood. Curr Diabetes Rev 2015;11(4):239-250 [FREE Full text] [doi: 10.2174/1573399811666150421114957] [Medline: 25901502]

7. Bryden KS, Dunger DB, Mayou RA, Peveler RC, Neil HAW. Poor prognosis of young adults with type 1 diabetes: a longitudinal study. Diabetes Care 2003 Apr;26(4):1052-1057. [doi: 10.2337/diacare.26.4.1052] [Medline: 12663572]

8. O'Hara MC, Hynes L, O'Donnell M, Nery N, Byrne M, Heller SR, Irish Type 1 Diabetes Young Adult Study Group. A systematic review of interventions to improve outcomes for young adults with Type 1 diabetes. Diabet Med 2017 Jun;34(6):753-769 [FREE Full text] [doi: 10.1111/dme.13276] [Medline: 27761951]

9. Martyn-Nemeth P, Duffecy J, Quinn L, Park C, Mihailescu D, Penckofer S. A cognitive behavioral therapy intervention to reduce fear of hypoglycemia in young adults with type 1 diabetes (FREE): study protocol for a randomized controlled trial. Trials 2019 Dec 30;20(1):796 [FREE Full text] [doi: 10.1186/s13063-019-3876-4] [Medline: 31888691]

10. Walsh DMJ, Hynes L, O'Hara MC, McSharry J, Dinneen SF, Byrne M. Embedding a user-centred approach in the development of complex behaviour change intervention to improve outcomes for young adults living with type 1 diabetes: The D1 Now Study. HRB Open Res 2018;1:8 [FREE Full text] [doi: 10.12688/hrbopenres.12803.2] [Medline: 32002502]

11. Albanese-O'Neill A, Beauchamp G, Thomas N, Westen SC, Johnson N, Schatz D, et al. Transition education for young adults with type 1 diabetes: pilot feasibility study for a group telehealth intervention. JMIR Diabetes 2018 Nov 05;3(4):e10909 [FREE Full text] [doi: 10.2196/10909] [Medline: $\underline{\text { 30401674] }}$

12. Wan W, Nathan AG, Skandari MR, Zarei P, Reid MW, Raymond JK, et al. Cost-effectiveness of shared telemedicine appointments in young adults with T1D: CoYoT1 trial. Diabetes Care 2019 Aug;42(8):1589-1592 [FREE Full text] [doi: 10.2337/dc19-0363] [Medline: 31189564]

13. Weigensberg MJ, Vigen C, Sequeira P, Spruijt-Metz D, Juarez M, Florindez D, et al. Diabetes empowerment council: integrative pilot intervention for transitioning young adults with type 1 diabetes. Glob Adv Health Med 2018;7:2164956118761808 [FREE Full text] [doi: 10.1177/2164956118761808] [Medline: 29552422]

14. Laffel LM, Kanapka LG, Beck RW, Bergamo K, Clements MA, Criego A, CGM Intervention in Teens and Young Adults with T1D (CITY) Study Group, CDE10. Effect of continuous glucose monitoring on glycemic control in adolescents and young adults with type 1 diabetes: a randomized clinical trial. JAMA 2020 Jun 16;323(23):2388-2396 [FREE Full text] [doi: 10.1001/jama.2020.6940] [Medline: 32543683]

15. Tougas ME, Hayden JA, McGrath PJ, Huguet A, Rozario S. A systematic review exploring the social cognitive theory of self-regulation as a framework for chronic health condition interventions. PLoS One 2015;10(8):e0134977 [FREE Full text] [doi: 10.1371/journal.pone.0134977] [Medline: 26252889]

16. Baker AC, Wiebe DJ, Kelly CS, Munion A, Butner JE, Swinyard MT, et al. Structural model of patient-centered communication and diabetes management in early emerging adults at the transfer to adult care. J Behav Med 2019 Oct;42(5):831-841 [FREE Full text] [doi: 10.1007/s10865-019-00012-9] [Medline: 30680592]

17. Wiebe DJ, Berg CA, Mello D, Kelly CS. Self- and social-regulation in type 1 diabetes management during late adolescence and emerging adulthood. Curr Diab Rep 2018 Mar 21;18(5):23. [doi: 10.1007/s11892-018-0995-3] [Medline: 29564640]

18. Perez KM, Patel NJ, Lord JH, Savin KL, Monzon AD, Whittemore R, et al. Executive function in adolescents with type 1 diabetes: relationship to adherence, glycemic control, and psychosocial outcomes. J Pediatr Psychol 2017 Jul 01;42(6):636-646 [FREE Full text] [doi: 10.1093/jpepsy/jsw093] [Medline: 28008003]

19. Wysocki T, Iannotti R, Weissberg-Benchell J, Laffel L, Hood K, Anderson B, Family Management of Childhood Diabetes Steering Committee. Diabetes problem solving by youths with type 1 diabetes and their caregivers: measurement, validation, and longitudinal associations with glycemic control. J Pediatr Psychol 2008 Sep;33(8):875-884 [FREE Full text] [doi: 10.1093/jpepsy/jsn024] [Medline: 18346973]

20. Johnston-Brooks CH, Lewis MA, Garg S. Self-efficacy impacts self-care and HbA1c in young adults with Type I diabetes. Psychosom Med 2002;64(1):43-51. [doi: 10.1097/00006842-200201000-00007] [Medline: 11818585]

21. Stanger C, Lansing AH, Scherer E, Budney A, Christiano AS, Casella SJ. A web-delivered multicomponent intervention for adolescents with poorly controlled type 1 diabetes: a pilot randomized controlled trial. Ann Behav Med 2018 Nov 12;52(12):1010-1022 [FREE Full text] [doi: 10.1093/abm/kay005] [Medline: 30418521]

22. Bickel WK, Moody L, Higgins ST. Some current dimensions of the behavioral economics of health-related behavior change. Prev Med 2016 Nov;92:16-23 [FRE Full text] [doi: 10.1016/j.ypmed.2016.06.002] [Medline: 27283095] 
23. Wong CA, Miller VA, Murphy K, Small D, Ford CA, Willi SM, et al. Effect of financial incentives on glucose monitoring adherence and glycemic control among adolescents and young adults with type 1 diabetes: a randomized clinical trial. JAMA Pediatr 2017 Dec 01;171(12):1176-1183. [doi: 10.1001/jamapediatrics.2017.3233] [Medline: 29059263]

24. Petry NM, Cengiz E, Wagner JA, Weyman K, Tichy E, Tamborlane WV. Testing for rewards: a pilot study to improve type 1 diabetes management in adolescents. Diabetes Care 2015 Oct;38(10):1952-1954 [FREE Full text] [doi: 10.2337/dc15-0765] [Medline: 26203061]

25. Raiff BR, Barrry VB, Ridenour TA, Jitnarin N. Internet-based incentives increase blood glucose testing with a non-adherent, diverse sample of teens with type 1 diabetes mellitus: a randomized controlled Trial. Transl Behav Med 2016 Jun;6(2):179-188 [FREE Full text] [doi: $\underline{10.1007 / \mathrm{s} 13142-016-0397-5]}$ [Medline: $\underline{\text { 27198235] }}$

26. Lansing AH, Stanger C, Budney A, Christiano AS, Casella SJ. Pilot study of a web-delivered multicomponent intervention for rural teens with poorly controlled type 1 diabetes. J Diabetes Res 2016;2016:1-8. [doi: 10.1155/2016/7485613]

27. Stanger C, Ryan SR, Delhey LM, Thrailkill K, Li Z, Li Z, et al. A multicomponent motivational intervention to improve adherence among adolescents with poorly controlled type 1 diabetes: a pilot study. J Pediatr Psychol 2013 Jul;38(6):629-637 [FREE Full text] [doi: 10.1093/jpepsy/jst032] [Medline: 23699750 ]

28. Pyatak EA, Carandang K, Vigen C, Blanchard J, Sequeira PA, Wood JR, et al. Resilient, Empowered, Active Living with Diabetes (REAL Diabetes) study: Methodology and baseline characteristics of a randomized controlled trial evaluating an occupation-based diabetes management intervention for young adults. Contemp Clin Trials 2017 Mar;54:8-17 [FREE Full text] [doi: 10.1016/j.cct.2016.12.025] [Medline: 28064028]

29. Nansel TR, Thomas DM, Liu A. Efficacy of a behavioral intervention for pediatric type 1 diabetes across income. Am J Prev Med 2015 Dec;49(6):930-934 [FREE Full text] [doi: 10.1016/j.amepre.2015.05.006] [Medline: 26231856]

30. Mulvaney SA, Rothman RL, Osborn CY, Lybarger C, Dietrich MS, Wallston KA. Self-management problem solving for adolescents with type 1 diabetes: intervention processes associated with an Internet program. Patient Educ Couns 2011 Nov;85(2):140-142 [FREE Full text] [doi: 10.1016/j.pec.2010.09.018] [Medline: 21030194]

31. Stetson B, Boren S, Leventhal H, Schlundt D, Glasgow R, Fisher E. Embracing the evidence on problem solving in diabetes self-management education and support. 2010. URL: https://selfcarejournal.com/wp-content/uploads/2015/09/Stetson-1.3. 83-99.pdf [accessed 2021-02-15]

32. Bell AC, D'Zurilla TJ. Problem-solving therapy for depression: a meta-analysis. Clin Psychol Rev 2009 Jun;29(4):348-353. [doi: 10.1016/j.cpr.2009.02.003] [Medline: 19299058]

33. Hill-Briggs F, Gemmell L. Problem solving in diabetes self-management and control: a systematic review of the literature. Diabetes Educ 2007;33(6):1032-1050. [doi: 10.1177/0145721707308412] [Medline: 18057272]

34. Zoffmann V, Lauritzen T. Guided self-determination improves life skills with type 1 diabetes and A1C in randomized controlled trial. Patient Educ Couns 2006 Dec;64(1-3):78-86. [doi: 10.1016/j.pec.2005.11.017] [Medline: 16720089]

35. Channon SJ, Huws-Thomas MV, Rollnick S, Hood K, Cannings-John RL, Rogers C, et al. A multicenter randomized controlled trial of motivational interviewing in teenagers with diabetes. Diabetes Care 2007 Jun;30(6):1390-1395. [doi: 10.2337/dc06-2260] [Medline: 17351283 ]

36. Mohr DC, Cuijpers P, Lehman K. Supportive accountability: a model for providing human support to enhance adherence to eHealth interventions. J Med Internet Res 2011 Mar;13(1):e30 [FREE Full text] [doi: 10.2196/jmir.1602] [Medline: 21393123]

37. Zarski A, Lehr D, Berking M, Riper H, Cuijpers P, Ebert DD. Adherence to Internet-Based Mobile-Supported Stress Management: A Pooled Analysis of Individual Participant Data From Three Randomized Controlled Trials. J Med Internet Res 2016 Jun 29;18(6):e146 [FREE Full text] [doi: 10.2196/jmir.4493] [Medline: 27357528]

38. Mohr DC, Duffecy J, Ho J, Kwasny M, Cai X, Burns MN, et al. A randomized controlled trial evaluating a manualized TeleCoaching protocol for improving adherence to a web-based intervention for the treatment of depression. PLoS One 2013 Aug;8(8):e70086 [FREE Full text] [doi: 10.1371/journal.pone.0070086] [Medline: 23990896]

39. Forand NR, Barnett JG, Strunk DR, Hindiyeh MU, Feinberg JE, Keefe JR. Efficacy of guided iCBT for depression and mediation of change by cognitive skill acquisition. Behav Ther 2018 Dec;49(2):295-307 [FREE Full text] [doi:

10.1016/j.beth.2017.04.004] [Medline: 29530267]

40. Brouwers RWM, Kraal JJ, Traa SCJ, Spee RF, Oostveen LMLC, Kemps HMC. Effects of cardiac telerehabilitation in patients with coronary artery disease using a personalised patient-centred web application: protocol for the SmartCare-CAD randomised controlled trial. BMC Cardiovasc Disord 2017 Dec 31;17(1):46 [FREE Full text] [doi:

10.1186/s12872-017-0477-6] [Medline: 28143388]

41. Wild SH, Hanley J, Lewis SC, McKnight JA, McCloughan LB, Padfield PL, et al. Supported telemonitoring and glycemic control in people with type 2 diabetes: the Telescot Diabetes Pragmatic Multicenter Randomized Controlled Trial. PLoS Med 2016 Jul;13(7):e1002098 [FREE Full text] [doi: 10.1371/journal.pmed.1002098] [Medline: 27458809]

42. Carter W, Fergus K, Ahmad S, McLeod D, Stephen J. Defining the role of the online therapeutic facilitator: principles and guidelines developed for Couplelinks, an online support program for couples affected by breast cancer. JMIR Cancer 2015 Apr 14;1(1):e4 [FREE Full text] [doi: 10.2196/cancer.3887] [Medline: 28410159] 
43. Titov N, Andrews G, Davies M, McIntyre K, Robinson E, Solley K. Internet treatment for depression: a randomized controlled trial comparing clinician vs. technician assistance. PLoS One 2010;5(6):e10939 [FREE Full text] [doi: 10.1371/journal.pone.0010939] [Medline: 20544030]

44. Baumeister H, Reichler L, Munzinger M, Lin J. The impact of guidance on Internet-based mental health interventions: a systematic review. Internet Interventions 2014 Oct;1(4):205-215. [doi: 10.1016/j.invent.2014.08.003]

45. Bender JL, Cyr AB, Arbuckle L, Ferris LE. Ethics and privacy implications of using the internet and social media to recruit participants for health research: a privacy-by-design framework for online recruitment. J Med Internet Res 2017 Apr 06;19(4):e104 [FREE Full text] [doi: 10.2196/jmir.7029] [Medline: 28385682]

46. Gelinas L, Pierce R, Winkler S, Cohen IG, Lynch HF, Bierer BE. Using social media as a research recruitment tool: ethical issues and recommendations. Am J Bioeth 2017 Mar;17(3):3-14 [FREE Full text] [doi: 10.1080/15265161.2016.1276644] [Medline: 28207365]

47. Chakraborty B, Collins LM, Strecher VJ, Murphy SA. Developing multicomponent interventions using fractional factorial designs. Stat Med 2009 Sep 20;28(21):2687-2708 [FREE Full text] [doi: 10.1002/sim.3643] [Medline: 19575485]

48. Collins LM, Dziak JJ, Kugler KC, Trail JB. Factorial experiments: efficient tools for evaluation of intervention components. Am J Prev Med 2014 Oct;47(4):498-504 [FREE Full text] [doi: 10.1016/j.amepre.2014.06.021] [Medline: 25092122]

49. Kugler KC, Trail JB, Dziak JJ, Collins LM. Effect coding versus dummy coding in analysis of data from factorial experiments. The Methodology Center, The Pennsylvania State University. University Park: The Methodology Cneter, Pennsylvania State University; 2012.

50. Collins LM, Dziak JJ, Li R. Design of experiments with multiple independent variables: a resource management perspective on complete and reduced factorial designs. Psychol Methods 2009 Sep;14(3):202-224 [FREE Full text] [doi: 10.1037/a0015826] [Medline: 19719358]

51. Collins L. Optimization of Behavioral, Biobehavioral, and Biomedical Interventions: The Multiphase Optimization Strategy (MOST). Cham: Springer; 2018.

52. Saghaei M, Saghaei S. Implementation of an open-source customizable minimization program for allocation of patients to parallel groups in clinical trials. J Biomed Sci Engin 2011;04(11):734-739. [doi: 10.4236/jbise.2011.411090]

53. Filler A, Kowatsch T, Haug S, Wahle F, Staake T, Fleisch E. MobileCoach: a novel open source platform for the design of evidence-based, scalable and low-cost behavioral health interventions: overview and preliminary evaluation in the public health context. MobileCoach: A novel open source platform for the design of evidence-based, scalable and low-cost behavioral health interventions: Overview and preliminary evaluation in the public health context. 2015 Wireless Telecommunications Symposium (WTS); 2015 Presented at: 2015 Wireless Telecommunications Symposium (WTS); 2015; New York. [doi: 10.1109/wts.2015.7117255]

54. Kowatsch T, Volland D, Shih I, Rüegger D, Künzler F, Barata F. Design and Evaluation of a Mobile Chat App for the Open Source Behavioral Health Intervention Platform Mobilecoach. Berlin: Springer; 2017.

55. MobileCoach. URL: https://www.mobile-coach.eu/ [accessed 2021-02-15]

56. Driscoll KA, Johnson SB, Hogan J, Gill E, Wright N, Deeb LC. Insulin bolusing software: the potential to optimize health outcomes in type 1 diabetes mellitus. J Diabetes Sci Technol 2013 May 01;7(3):646-652 [FREE Full text] [doi: 10.1177/193229681300700309] [Medline: 23759397]

57. American Diabetes Association. Standards of Medical Care in Diabetes-2016 Abridged for Primary Care Providers. Clin Diabetes 2016 Jan;34(1):3-21 [FREE Full text] [doi: 10.2337/diaclin.34.1.3] [Medline: 26807004]

58. Mazur J, Logue A. Choice in a "self-control" paradigm: effects of a fading procedure. J Exp Anal Behav 1978 Jul;30(1):11-17 [FREE Full text] [doi: 10.1901/jeab.1978.30-11] [Medline: 16812082]

59. Fisher WW, Thompson RH, Hagopian LP, Bowman LG, Krug A. Facilitating tolerance of delayed reinforcement during functional communication training. Behav Modif 2000 Jan;24(1):3-29. [doi: 10.1177/0145445500241001] [Medline: 10641365]

60. Dixon M, Hayes L, Binder L, Manthey S, Sigman C, Zdanowski D. Using a self-control training procedure to increase appropriate behavior. J Appl Behav Anal 1998;31(2):203-210 [FREE Full text] [doi: 10.1901/jaba.1998.31-203] [Medline: 9652100]

61. Dixon M, Holcomb S. Teaching self-control to small groups of dually diagnosed adults. J Appl Behav Anal 2000;33(4):611-614 [FREE Full text] [doi: 10.1901/jaba.2000.33-611] [Medline: 11214034]

62. Schweitzer J, Sulzer-Azaroff B. Self-control: teaching tolerance for delay in impulsive children. J Exp Anal Behav 1988 Sep;50(2):173-186 [FREE Full text] [doi: 10.1901/jeab.1988.50-173] [Medline: $\underline{3193054}$ ]

63. Channon S, Huws-Thomas M, Gregory J, Rollnick S. Motivational interviewing with teenagers with diabetes. Clin Child Psychol Psychiatry 2016 Jul 26;10(1):43-51. [doi: 10.1177/1359104505048790]

64. Nezu AM. Efficacy of a social problem-solving therapy approach for unipolar depression. J Consult Clin Psychol 1986 Apr;54(2):196-202. [doi: 10.1037//0022-006x.54.2.196] [Medline: 3700806]

65. Rollnick S, Mason P, Butler C. Health Behavior Change: A Guide for Practitioners. London: Churchill Livingstone; 1999.

66. Sturt J, Dennick K, Hessler D, Hunter BM, Oliver J, Fisher L. Effective interventions for reducing diabetes distress: systematic review and meta-analysis. Int Diabetes Nurs 2015 Jul 06;12(2):40-55. [doi: 10.1179/2057332415Y.0000000004] 
67. Greaves CJ, Middlebrooke A, O'Loughlin L, Holland S, Piper J, Steele A, et al. Motivational interviewing for modifying diabetes risk: a randomised controlled trial. Br J Gen Pract 2008 Aug;58(553):535-540 [FREE Full text] [doi: 10.3399/bjgp08X319648] [Medline: 18682011 ]

68. Carter B. Children's Health and Illness Recovery Program (CHIRP) Clinician's Handbook 2015. London: Oxford University Press; 2015.

69. Williams VF, Smith AA, Villanti AC, Rath JM, Hair EC, Cantrell J, et al. Validity of a subjective financial situation measure to assess socioeconomic status in US young adults. J Public Health Manag Pract 2016 Oct 28;23(5):487-495. [doi: 10.1097/PHH.0000000000000468] [Medline: 27798530]

70. Cengiz E, Xing D, Wong JC, Wolfsdorf JI, Haymond MW, Rewers A, T1D Exchange Clinic Network. Severe hypoglycemia and diabetic ketoacidosis among youth with type 1 diabetes in the T1D Exchange clinic registry. Pediatr Diabetes 2013 Sep;14(6):447-454 [FREE Full text] [doi: 10.1111/pedi.12030] [Medline: 23469984]

71. Sepah SC, Jiang L, Peters AL. Long-term outcomes of a Web-based diabetes prevention program: 2-year results of a single-arm longitudinal study. J Med Internet Res 2015;17(4):e92 [FREE Full text] [doi: 10.2196/jmir.4052] [Medline: 25863515]

72. Iannotti RJ, Schneider S, Nansel TR, Haynie DL, Plotnick LP, Clark LM, et al. Self-efficacy, outcome expectations, and diabetes self-management in adolescents with type 1 diabetes. J Dev Behav Pediatr 2006 Apr;27(2):98-105. [doi: 10.1097/00004703-200604000-00003] [Medline: 16682872]

73. D'Zurilla T, Nezu A, Maydeu-Olivares A. Test Manual for the Social Problem-Solving Inventory-Revised (SPSI-R). Stony Brook: State University of New York at Stony Brook; 1996.

74. Dreer LE, Berry J, Rivera P, Snow M, Elliott TR, Miller D, et al. Efficient assessment of social problem-solving abilities in medical and rehabilitation settings: a Rasch analysis of the Social Problem-Solving Inventory-Revised. J Clin Psychol 2009 Jul;65(7):653-669 [FREE Full text] [doi: 10.1002/jclp.20573] [Medline: 19267395]

75. Fisher L, Polonsky WH, Hessler DM, Masharani U, Blumer I, Peters AL, et al. Understanding the sources of diabetes distress in adults with type 1 diabetes. J Diabetes Complications 2015;29(4):572-577 [FREE Full text] [doi: 10.1016/j.jdiacomp.2015.01.012] [Medline: 25765489]

76. Fisher L, Hessler D, Polonsky W, Strycker L, Masharani U, Peters A. Diabetes distress in adults with type 1 diabetes: prevalence, incidence and change over time. J Diabetes Complications 2016 Aug;30(6):1123-1128 [FREE Full text] [doi: 10.1016/j.jdiacomp.2016.03.032] [Medline: 27118163]

77. Locke BD, McAleavey AA, Zhao Y, Lei P, Hayes JA, Castonguay LG, et al. Development and initial validation of the Counseling Center Assessment of Psychological Symptoms-34 (CCAPS-34). Measur Eval Couns Devel 2017 Mar 10;45(3):151-169. [doi: 10.1177/0748175611432642]

78. Eisenberg I, Bissett P, Canning J, Dallery J, Enkavi A, Whitfield-Gabrieli S, et al. Applying novel technologies and methods to inform the ontology of self-regulation. Behav Res Ther 2018 Feb;101:46-57 [FREE Full text] [doi:

10.1016/j.brat.2017.09.014] [Medline: 29066077]

79. Shields SA, Mallory ME, Simon A. The Body Awareness Questionnaire: reliability and validity. J Personality Assess 1989 Dec;53(4):802-815. [doi: 10.1207/s15327752jpa5304 16]

80. Gold AE, MacLeod KM, Frier BM. Frequency of severe hypoglycemia in patients with type I diabetes with impaired awareness of hypoglycemia. Diabetes Care 1994 Jul;17(7):697-703. [doi: 10.2337/diacare.17.7.697] [Medline: 7924780]

81. Parasuraman A, Colby CL. An updated and streamlined Technology Readiness Index: TRI 2. J Serv Res 2014 Jun 22;18(1):59-74. [doi: 10.1177/1094670514539730]

82. Venkatesh $\mathrm{V}$, Thong $\mathrm{J}, \mathrm{Xu} \mathrm{X}$. Consumer acceptance and use of information technology: extending the unified theory of acceptance and use of technology. MIS Quarterly 2012;36(1):157. [doi: 10.2307/41410412]

83. Johnston L, Bachman J, O'Malley P, Schulenberg J. Monitoring the future: a continuing study of American youth (12th-grade survey). Inter-university Consortium for Political and Social Research 2018. [doi: 10.3886/ICPSR37416.v1]

84. SAMHSA. 2020 National Survey on Drug Use and Health (NSDUH): CAI specifications for programming (English version). Rockville: Center for Behavioral Health Statistics and Quality; 2020. URL: https://www.samhsa.gov/data/sites/default/ files/reports/rpt23244/NSDUHmrbCAISpecs2020.pdf [accessed 2021-02-12]

85. Wu L, McNeely J, Subramaniam GA, Sharma G, VanVeldhuisen P, Schwartz RP. Design of the NIDA clinical trials network validation study of tobacco, alcohol, prescription medications, and substance use/misuse (TAPS) tool. Contemp Clin Trials 2016 Sep;50:90-97 [FREE Full text] [doi: 10.1016/j.cct.2016.07.013] [Medline: 27444426]

86. Falkenström F, Hatcher RL, Skjulsvik T, Larsson MH, Holmqvist R. Development and validation of a 6-item working alliance questionnaire for repeated administrations during psychotherapy. Psychol Assess 2015 Mar;27(1):169-183. [doi: 10.1037/pas0000038] [Medline: 25346997]

87. Kiluk BD, Serafini K, Frankforter T, Nich C, Carroll KM. Only connect: the working alliance in computer-based cognitive behavioral therapy. Behav Res Ther 2014 Dec;63:139-146 [FREE Full text] [doi: 10.1016/j.brat.2014.10.003] [Medline: 25461789]

88. Bickmore TW, Mitchell SE, Jack BW, Paasche-Orlow MK, Pfeifer LM, Odonnell J. Response to a relational agent by hospital patients with depressive symptoms. Interact Comput 2010 Jul 01;22(4):289-298 [FREE Full text] [doi: 10.1016/j.intcom.2009.12.001] [Medline: 20628581] 
89. Lund A. Measuring usability with the USE questionnaire. 2001. URL: https://www.researchgate.net/publication/ 230786746 Measuring Usability with the USE Questionnaire [accessed 2021-02-12]

90. Wixom BH, Todd PA. A theoretical integration of user satisfaction and technology acceptance. Inf Syst Res 2005 Mar;16(1):85-102. [doi: 10.1287/isre.1050.0042]

91. Petry NM, Alessi SM, Ledgerwood DM, Sierra S. Psychometric properties of the contingency management competence scale. Drug Alcohol Depend 2010 Jun 01;109(1-3):167-174 [FREE Full text] [doi: 10.1016/j.drugalcdep.2009.12.027] [Medline: 20149950]

92. Cohen J. Statistical Power Analysis for the Behavioral Sciences. New York: Academic Press; 1988.

93. Smith R, Coffman D, Zhu X. Investigating an intervention's causal story: mediation analysis using a factorial experiment and multiple mediators. In: Collins L, editor. Optimization of Behavioral, Biobehavioral, and Biomedical Interventions Statistics for Social and Behavioral Sciences. Cham: Springer; 2018.

94. MacKinnon DP, Fairchild AJ, Fritz MS. Mediation analysis. Annu Rev Psychol 2007;58:593-614 [FREE Full text] [doi: 10.1146/annurev.psych.58.110405.085542] [Medline: 16968208 ]

95. Yardley L, Spring BJ, Riper H, Morrison LG, Crane DH, Curtis K, et al. Understanding and promoting effective engagement with digital behavior change interventions. Am J Prev Med 2016 Nov;51(5):833-842. [doi: 10.1016/j.amepre.2016.06.015] [Medline: 27745683]

96. Diabetes Control and Complications Trial Research Group. Effect of intensive diabetes treatment on the development and progression of long-term complications in adolescents with insulin-dependent diabetes mellitus: Diabetes Control and Complications Trial. J Pediatr 1994 Aug;125(2):177-188. [Medline: 8040759]

97. Clements MA, Foster NC, Maahs DM, Schatz DA, Olson BA, Tsalikian E, T1D Exchange Clinic Network. Hemoglobin A1c (HbA1c) changes over time among adolescent and young adult participants in the T1D exchange clinic registry. Pediatr Diabetes 2016 Dec;17(5):327-336. [doi: 10.1111/pedi.12295] [Medline: 26153338]

98. Kibbey KJ, Speight J, Wong JLA, Smith LA, Teede HJ. Diabetes care provision: barriers, enablers and service needs of young adults with Type 1 diabetes from a region of social disadvantage. Diabet Med 2013 May 30;30(7):878-884. [doi: 10.1111/dme.12227]

99. Moström P, Ahlén E, Imberg H, Hansson P, Lind M. Adherence of self-monitoring of blood glucose in persons with type 1 diabetes in Sweden. BMJ Open Diabetes Res Care 2017;5(1):e000342 [FREE Full text] [doi: 10.1136/bmjdrc-2016-000342] [Medline: 28611921]

100. Picard S, Hanaire H, Baillot-Rudoni S, Gilbert-Bonnemaison E, Not D, Reznik Y, et al. Evaluation of the adherence to continuous glucose monitoring in the management of type 1 diabetes patients on sensor-augmented pump therapy: the SENLOCOR Study. Diabetes Technol Ther 2016 Mar;18(3):127-135. [doi: 10.1089/dia.2015.0240] [Medline: 26950530]

101. Danne T, Nimri R, Battelino T, Bergenstal RM, Close KL, DeVries JH, et al. International consensus on use of continuous glucose monitoring. Diabetes Care 2017 Dec;40(12):1631-1640 [FREE Full text] [doi: 10.2337/dc17-1600] [Medline: 29162583]

102. Marteau TM, Dormandy E. Facilitating informed choice in prenatal testing: how well are we doing? Am J Med Genet 2001;106(3):185-190. [doi: 10.1002/ajmg.10006] [Medline: 11778978 ]

103. Patton SR, DeLurgio SA, Fridlington A, Cohoon C, Turpin AL, Clements MA. Frequency of mealtime insulin bolus predicts glycated hemoglobin in youths with type 1 diabetes. Diabetes Technol Ther 2014 Aug;16(8):519-523 [FREE Full text] [doi: 10.1089/dia.2013.0356] [Medline: 24773597]

104. Lau YN, Korula S, Chan AK, Heels K, Krass I, Ambler G. Analysis of insulin pump settings in children and adolescents with type 1 diabetes mellitus. Pediatr Diabetes 2016 Aug;17(5):319-326. [doi: 10.1111/pedi.12285] [Medline: 25998469]

105. O'Connell M, Donath S, Cameron F. Poor adherence to integral daily tasks limits the efficacy of CSII in youth. Pediatr Diabetes 2011 Sep;12(6):556-559. [doi: 10.1111/j.1399-5448.2010.00740.x] [Medline: 21466646]

106. Deeb A, Abu-Awad S, Abood S, El-Abiary M, Al-Jubeh J, Yousef H, et al. Important determinants of diabetes control in insulin pump therapy in patients with type 1 diabetes mellitus. Diabetes Technol Ther 2015 Mar;17(3):166-170. [doi: 10.1089/dia.2014.0224] [Medline: 25513744]

107. Clements MA, DeLurgio SA, Williams DD, Habib S, Halpin K, Patton SR. Association of HbA1c to BOLUS scores among youths with type 1 diabetes. Diabetes Technol Ther 2016 Jun;18(6):351-359 [FREE Full text] [doi: 10.1089/dia.2015.0352] [Medline: 27258122]

108. Cukierman-Yaffe T, Konvalina N, Cohen O. Key elements for successful intensive insulin pump therapy in individuals with type 1 diabetes. Diabetes Res Clin Pract 2011 Apr;92(1):69-73. [doi: 10.1016/j.diabres.2011.01.002] [Medline: 21292340]

109. Franklin V. Influences on technology use and efficacy in type 1 diabetes. J Diabetes Sci Technol 2016 May;10(3):647-655 [FREE Full text] [doi: 10.1177/1932296816639315] [Medline: 27022096]

110. Grando MA, Bayuk M, Karway G, Corrette K, Groat D, Cook CB, et al. Patient perception and satisfaction with insulin pump system: pilot user experience survey. J Diabetes Sci Technol 2019 Nov;13(6):1142-1148 [FREE Full text] [doi: 10.1177/1932296819843146] [Medline: 31055947]

111. Bally L, Thabit H, Hovorka R. Closed-loop for type 1 diabetes: an introduction and appraisal for the generalist. BMC Med 2017 Jan 23;15(1):14 [FREE Full text] [doi: 10.1186/s12916-017-0794-8] [Medline: 28114938] 
112. Messer LH, Johnson R, Driscoll KA, Jones J. Best friend or spy: a qualitative meta-synthesis on the impact of continuous glucose monitoring on life with Type 1 diabetes. Diabet Med 2018 Apr;35(4):409-418. [doi: 10.1111/dme.13568] [Medline: 29247556]

113. Gonder-Frederick L, Shepard J, Peterson N. Closed-loop glucose control: psychological and behavioral considerations. J Diabetes Sci Technol 2011 Nov 01;5(6):1387-1395 [FREE Full text] [doi: 10.1177/193229681100500610] [Medline: 22226256]

114. Messer LH, Berget C, Forlenza GP. A clinical guide to advanced diabetes devices and closed-loop systems using the CARES paradigm. Diabetes Technol Ther 2019 Aug;21(8):462-469 [FREE Full text] [doi: 10.1089/dia.2019.0105] [Medline: 31140878]

115. Tauschmann M, Thabit H, Bally L, Allen JM, Hartnell S, Wilinska ME, APCam11 Consortium. Closed-loop insulin delivery in suboptimally controlled type 1 diabetes: a multicentre, 12-week randomised trial. Lancet 2018 Dec 13;392(10155):1321-1329 [FREE Full text] [doi: 10.1016/S0140-6736(18)31947-0] [Medline: $\underline{30292578]}$

116. Nainggolan L. Over One Third of Type 1 Diabetes Patients Quit Closed-Loop System. Medscape. 2019 Mar 23. URL: http://www.medscape.com/viewarticle/910854 [accessed 2021-02-12]

117. Kullgren JT, Hafez D, Fedewa A, Heisler M. A scoping review of behavioral economic interventions for prevention and treatment of type 2 diabetes mellitus. Curr Diab Rep 2017 Sep;17(9):73 [FREE Full text] [doi: 10.1007/s11892-017-0894-z] [Medline: 28755061]

118. Cameron J, Banko KM, Pierce WD. Pervasive negative effects of rewards on intrinsic motivation: the myth continues. Behav Anal 2001;24(1):1-44 [FREE Full text] [doi: 10.1007/BF03392017] [Medline: 22478353]

119. Promberger M, Marteau TM. When do financial incentives reduce intrinsic motivation? Comparing behaviors studied in psychological and economic literatures. Health Psychol 2013 Sep;32(9):950-957 [FREE Full text] [doi: 10.1037/a0032727] [Medline: 24001245]

120. Ledgerwood DM, Petry NM. Does contingency management affect motivation to change substance use? Drug Alcohol Depend 2006 Jun 09;83(1):65-72. [doi: 10.1016/j.drugalcdep.2005.10.012] [Medline: 16310974]

121. Regier PS, Redish AD. Contingency management and deliberative decision-making processes. Front Psychiatry 2015;6:76 [FREE Full text] [doi: 10.3389/fpsyt.2015.00076] [Medline: 26082725]

122. Loewenstein G, Price J, Volpp K. Habit formation in children: evidence from incentives for healthy eating. J Health Econ 2016 Jan;45:47-54. [doi: 10.1016/j.jhealeco.2015.11.004] [Medline: 26717440]

123. Gardner B, de Bruijn G, Lally P. A systematic review and meta-analysis of applications of the Self-Report Habit Index to nutrition and physical activity behaviours. Ann Behav Med 2011 Oct;42(2):174-187. [doi: 10.1007/s12160-011-9282-0] [Medline: 21626256]

124. Gardner B. A review and analysis of the use of 'habit' in understanding, predicting and influencing health-related behaviour. Health Psychol Rev 2015;9(3):277-295 [FREE Full text] [doi: 10.1080/17437199.2013.876238] [Medline: 25207647]

125. DePhilippis D, Petry NM, Bonn-Miller MO, Rosenbach SB, McKay JR. The national implementation of Contingency Management (CM) in the Department of Veterans Affairs: Attendance at CM sessions and substance use outcomes. Drug Alcohol Depend 2018 Apr 01;185:367-373 [FREE Full text] [doi: 10.1016/j.drugalcdep.2017.12.020] [Medline: 29524874]

126. Mattke S, Kapinos K, Caloyeras JP, Taylor EA, Batorsky B, Liu H, et al. Workplace wellness programs: services offered, participation, and incentives. Rand Health Q 2015 Nov 30;5(2):7 [FREE Full text] [Medline: 28083383]

127. Misra-Hebert AD, Hu B, Le PH, Rothberg MB. Effect of health plan financial incentive offering on employees with prediabetes. Am J Med 2018 Mar;131(3):293-299 [FREE Full text] [doi: 10.1016/j.amjmed.2017.09.024] [Medline: 29024625]

128. Misra-Hebert AD, Hu B, Taksler G, Zimmerman R, Rothberg MB. Financial incentives and diabetes disease control in employees: a retrospective cohort analysis. J Gen Intern Med 2016 Aug;31(8):871-877 [FREE Full text] [doi: 10.1007/s11606-016-3686-2] [Medline: 27067350]

129. Fernandes R, Chinn CC, Li D, Frankland TB, Wang CM, Smith MD, et al. A randomized controlled trial of financial incentives for medicaid beneficiaries with diabetes. Perm J 2018;22:17-080 [FREE Full text] [doi: 10.7812/TPP/17-080] [Medline: 29401049]

130. Fernandes R, Chinn CC, Li D, Halliday T, Frankland TB, Wang CMB, et al. Financial incentives for medicaid beneficiaries with diabetes: lessons learned from HI-PRAISE, an observational study and randomized controlled trial. Am J Health Promot 2018 Sep;32(7):1498-1501. [doi: 10.1177/0890117117746335] [Medline: 29277099]

131. Kranker K. The efficacy of using financial incentives to change unhealthy behaviors among a rural chronically ill and uninsured population. Am J Health Promot 2018 Feb;32(2):301-311. [doi: 10.1177/0890117117696621] [Medline: 28279086]

132. Gilmer T, O'Connor PJ, Schiff JS, Taylor G, Vazquez-Benitez G, Garrett JE, et al. Cost-effectiveness of a community-based diabetes prevention program with participation incentives for medicaid beneficiaries. Health Serv Res 2018 Dec;53(6):4704-4724 [FREE Full text] [doi: 10.1111/1475-6773.12973] [Medline: 29770445]

133. VanEpps EM, Troxel AB, Villamil E, Saulsgiver KA, Zhu J, Chin J, et al. Financial incentives for chronic disease management: results and limitations of 2 randomized clinical trials with new york medicaid patients. Am J Health Promot 2018 Sep;32(7):1537-1543 [FREE Full text] [doi: 10.1177/0890117117753986] [Medline: 29390862]

134. Center for Digital Health Interventions. URL: www.c4dhi.org [accessed 2021-02-15] 


\section{Abbreviations}

CGM: continuous glucose monitor

CSII: continuous subcutaneous insulin infusion

CSS: Christian Social Health Insurance Company of Switzerland

SEM: structural equation modeling

$\mathbf{H b A}_{1 \mathbf{c}}$ : hemoglobin $\mathrm{A}_{1 \mathrm{c}}$

LMM: linear mixed effects model

MDI: multiple daily injections

SMBG: self-monitored blood glucose

T1D: type 1 diabetes

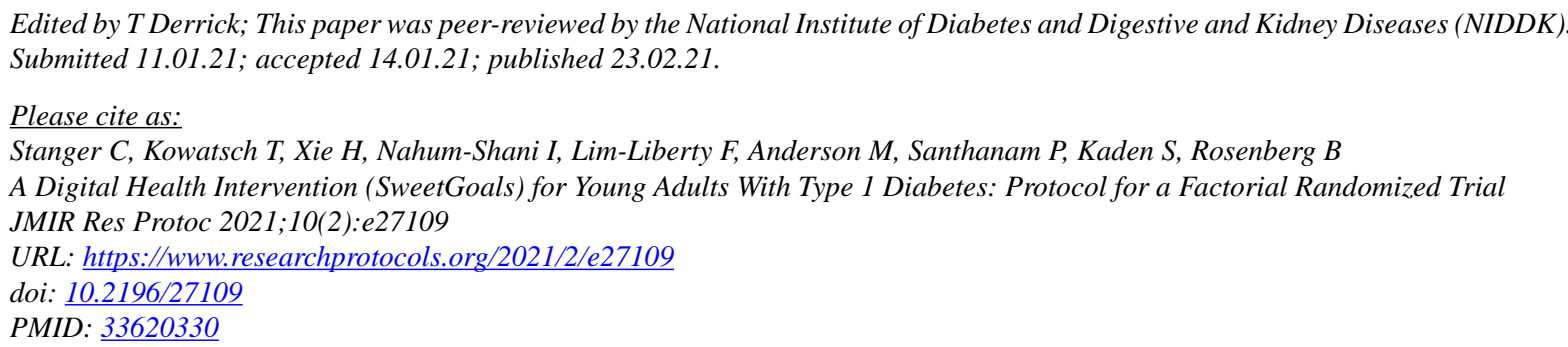

(C) Catherine Stanger, Tobias Kowatsch, Haiyi Xie, Inbal Nahum-Shani, Frances Lim-Liberty, Molly Anderson, Prabhakaran Santhanam, Sarah Kaden, Briana Rosenberg. Originally published in JMIR Research Protocols (http://www.researchprotocols.org), 23.02.2021. This is an open-access article distributed under the terms of the Creative Commons Attribution License (https://creativecommons.org/licenses/by/4.0/), which permits unrestricted use, distribution, and reproduction in any medium, provided the original work, first published in JMIR Research Protocols, is properly cited. The complete bibliographic information, a link to the original publication on http://www.researchprotocols.org, as well as this copyright and license information must be included. 